\title{
Slovenska zgodovinska avantgarda v kontekstu prve svetovne vojne, nacionalizmov in fašizma: primer Antona Podbevška
}

\author{
Marija Jurić Pahor
}

Inštitut za narodnostna vprašanja, Erjavčeva 26, 1000 Ljubljana

https://orcid.org/0000-0003-3408-1219

juric.pahor@alice.it

Za slovensko zgodovinsko avantgardo 1915-1927 je značilno, da se je oblikovala v kontekstu izkušnje prve svetoune vojne, vzpona nacionalizmov in italijanskega fašizma. Prispevek posebno pozornost posveča Antonu Podbevšku, ki velja za prvega slovenskega avantgardnega umetnika, a tudi za nekoga, ki je s svojimi literarnimi nastopi in pesnitvami "dregnil v središčni živec slovenskega kulturnega prostora Svojemu občinstvu se je predstavljal z imenom in naslovom svoje pesniške zbirke: Anton Podberšek - Človek z bombami. $O$ naslovu zbirke je Podbevšek dejal, da je nastala v skladu s takratnim vojnim časom. Prispevek ugovarja predpostavki, da se je Podbevšek na začetku svoje pesniške poti navduševal nad futurizmom in da ga je vojna pod futurističnim vplivom "magično pritegovala". Ponazori, da že cikel pesmi "Žolta pisma" daje bolj kot na futuristične jezikoune eksperimente misliti na vdor strahot vojne in na govorico travme. Iz analize izhaja, da sta ubeseditev in čutnokonkretna inscenacija doživete vojne groze onkraj estetizacij bistveni značilnosti Podberškove umetnosti. Številni sodobniki so se v njej »intuitivno «prepoznali, jo simpatetično podoživljali. Kljub fascinaciji, ki jo je vzbujala, se je morala ukloniti nacionalistično in/ali militantno navdihnjenim "graditeljem Bodočnosti Prispevek ogovarja tudi konstrukt "balkanskega barbarogenija in ambivalentni odnos (zlasti primorskih) slovenskih avantgardistov do italijanskega futurizma zlasti zaradi njegovih povezav z iredentizmom in fašizmom.

Ključne besede: slovenska književnost / zgodovinska avantgarda / Podbevšek, Anton / prva svetovna vojna / futurizem / nacionalizem / italijanski fašizem 


\section{Uvod: »Anton Podbevšek, človek z bombami«}

Pesniški ustvarjalni čas Antona Podbevška zamejujeta letnici 1915 in 1925 (Poniž, "Sedem《 9). Prva je hkrati začetek slovenskih zgodovinskih avantgard in prvi Podbevškov poskus, da bi s ciklom pesmi, ki mu je dal naslov Žolta pisma, stopil pred slovensko literarno javnost. Druga letnica, izid Podbevškove edine pesniške zbirke Človek z bombami, pa le rahlo odstopa od letnice konca slovenskih zgodovinskih avantgard, 1927 (Poniž, "Sedem《 9). Obe letnici sta povezani s prvo svetovno vojno. Prva se nanaša na mlade pesnike in umetnike, ki so pod neposrednim vtisom vojne in radikalnih sprememb, ki sta jih po njej doživeli kultura in družba, razvili prepričanje, da je vsa dotedanja umetnost "mrtva", "zastarela", "pasatistična" in da tako z vsebinskega kot z oblikovnega vidika terja prelom in novo, avantgardno pojmovanje vloge umetnosti. Druga letnica pomeni pomik v novo družbeno realnost vzpenjajočih se nacionalizmov in italijanskega fašizma, ki umetnikom niso več dopuščali, da bi razgaljali travmatizirajočo podobo vojne. Umakniti so se morali tudi liki strtih vojakov, pohabljencev, podobe napetih bivanjskih stanj, apokaliptična videnja, kakor jih zgovorno izpričujejo tudi Podbevškove pesnitve. Podbevšek se je leta 1927 umaknil iz žive umetniške prakse in javne sfere »v zasebnost družinskega življenja«, "v tridesetih letih ga tudi na časnikarskem prizorišču ne zasledimo več» (Dović, Mož 69).

Pomenljivo je, da je tudi Podbevškova pesniška zbirka Človek z bombami izšla šele leta 1925, dobrih pet let za tem, ko je kot pesnik umolknil, in sicer v samozaložbi. Toda dejstvo, da je svoje pesmi iz zbirke še naprej predstavljal poslušalcem njegovih soarej (Dović, Mož 61), daje ob grozotah vojne, ki je literarne ustvarjalce silila v "pesniški molk «", misliti tudi na tedanjo avantgardistično umetniško držo, za katero je bilo značilno, da je zavračala tiste determinacije, ki so esencialne za avtonomno umetnost, na primer ločenost umetnosti od življenjske prakse. Avantgardna umetnost je bila integrirana v življenje samo, usmerjena $\mathrm{k}$ ljudem, napeljala pa je tudi $\mathrm{k}$ politizaciji umetnosti in spreminjanju družbe (Bürger 53-54) ter implicirala v tem smislu tudi provokacijo ali škandal. O naslovu svoje pesniške zbirke je Podbevšek več kot trideset let po njenem izidu dejal, da ga je izbral "v skladu $s$ takratnim vojnim časom» (Kos, „Vprašanje« 10). Kaj lahko pa so ga

${ }^{1}$ "Wo sind Worte für das Erleben" (Kje so besede za doživeto) se glasi naslov monografije, s katerim Georg Philipp Rehage tematizira "lirični prikaz prve svetovne vojne $v$ francoski in nemški avantgardi« (podnaslov). 
pri izbiri naslova navdihnili tudi italijanski futuristi, ki so svoje proste verze imenovali "bombe in torpedovke« (Gruden 334), prav tako pa velja poudariti, da se Podbevšek za razliko od italijanskih futuristov nad vojno nikdar ni navduševal.

\section{Zavest o pogojenosti literature/estetike z vojno}

Očitno je, da je Podbevšek s svojimi pesnitvami, predvsem pa z njegovimi nastopi, ki jih je mogoče vzporejati s provokativnimi, a tudi odobravanje izzivajočimi večeri - seratami ali soarejami - sosednjih in drugih avantgard (Baumgarth 36-51), dregnil v »središčni živec slovenskega kulturnega polja (Dović, Mož 67). Podbevšek je svoje "recitacijske večere" prirejal že od leta 1914 dalje: najprej kot gimnazijec v Novem mestu in okolici, septembra 1920 jih je »kronal z 'novomeško pomladjo'" (Kocijan 42), nakar je začel z nastopi v Ljubljani in drugod po Sloveniji. Ti večeri, ki jih je z improvizacijami na klavirju večkrat spremljal skladatelj Marij Kogoj, so se po navedbah mariborskega dnevnika Tabor iz leta 1921 običajno začeli tako, da se je njihov glavni protagonist svojemu občinstvu predstavil z besedami: "Anton Podbevšek, človek z bombami, je pričel s svojim preroško pojočim, pridigarsko pobarvanim glasom recitirati svoje pesnitve. Občinstvo je strmelo, poslušalo, toda razumelo ni ničesar." (Vrečko, "Labodovci« 51)

Če je občinstvo "strmelo, poslušalo« in večkrat prešlo tudi v »buren aplavz« (Stelè 59), se zdi, da je Podbevška še kako dobro razumelo, pa najsi bolj na podzavestni kot na zavestni ravni. Na sozvočje občinstva z umetnikom je denimo opozoril Alojzij Remec, ko je govoril o Podbevškovem "recitacijskem večeru" 12 . novembra $1920 \mathrm{v}$ ljubljanskem Narodnem gledališču. Čeprav mu na tem večeru marsikaj ni bilo všeč - na primer "samozavest človeka z bombami«, dozdevna duševna sorodnost z Marinettijem - daje vedeti, da so pesnikove podobe posebno odmevale pri tistih, ki so služili v vojski, in da so se, še zlasti Plesalec $v$ ječi, globoko dotaknile tudi njega samega, nanj »delovale kakor Barbusse s svojim 'Le feu'«(Remec 2). Nemajhen del poslušalcev pa je intuitivno "razumel« tudi Kogojevo glasbo, saj je Fran Kimovec o njej zapisal, da je bila lažje dostopna glasbeno neukim kot pa glasbenikom (ti glasbeno znanje potrebujejo kot Prokrustovo posteljo in Kogoja tlačijo vanjo) (Kimovec 315).

Podbevšek je na odru uprizarjal »besedno umetnost «, ki daje misliti na istoimenski estetski postopek, ki so ga razvili v krogu okoli nemške revije Der Sturm. Poudarek je bil na "čisti materialnosti besede» 
(zvočnem valovanju) onkraj govorčeve intence, ki jo je Kogoj s svojo glasbo, "ki sestoja iz valov ter deluje z ritmiko« onkraj utečenih predstav in občutij (Rehar 2), le še podkrepil. Prevladovalo je mnenje, da intencionalni jezik besedo le potvori in hkrati onemogoča najdenje besed za tisto, kar se je zdelo novo, še neubesedeno, ali neznosno v doživetem (Fähnders 186-189). Beseda je bila podrejena funkciji - prevajati pulzije telesa, zaobjete $\mathrm{v}$ razpoloženju, $\mathrm{v}$ katerem se zunanja resničnost ponotranja, prežame s subjektivnostjo - in zato lahko preneha biti beseda, da bi se izražala neposredno, brez filtra poetološko-retoričnih kodov. Pesniški zgled za to »besedno umetnost « je bila tako imenovana "doživljajska lirika Augusta Stramma v smislu, da je reinscenirala travmatične izkušnje prve svetovne vojne (Rehage 163-209). France Stelè, ki je bil kot vojak na fronti v Galiciji, je tudi pesnitve Podbevška, še zlasti njegov "recitacijski večer « v že omenjenem Narodnem gledališču v Ljubljani 12. novembra 1920, označil kot »velik doživljaj«:

Podbevšek je podal kos življenja, to smo čutili vsi; podal ga je za naše razmere v novi obliki, katere revolucionarnost sega od zunanje (vidne) oblike umotvora preko forme (slišne oblike), ki se javlja v ritmu, zvokovnih kombinacijah, muzikaličnih elementih ter fantastično-barvnem ozadju njegovega aranžmaja do vsebine same, ki [...] je pa odpovedno formi razkosana na elemente, ki se vedno znova vzžarevajo kot rakete: forma in doživljaj, obnovljen v spominu, dvignjen iz podzavesti v zavestno jasnino, sta vselej žarka in zato oba presenetita. (Stelè 59)

Povedna v tem kontekstu je na primer pesnitev Plesalec v ječi, ki jo je Podbevšek kot zadnjo uvrstil v zbirko Človek z bombami in se prav tako navezuje na grozote vojne. Prvoosebni pripovedovalec je ves čas $\mathrm{v}$ vojaški ječi, v brezupnem solipsizmu, njegova domišljija deluje mrzlično, konec pesnitve pa izzveneva $\mathrm{v}$ ustvarjalnem zanosu, ki implicira voljo do (pre)živetja vsemu obstoječemu navkljub, stopanje v stik z lastno vitalnostjo in podobo, ki bi znala čudežno oživiti tisto, kar je bilo v njem ubito.

In moj glas se je tresel v prečudnih valovih, ko sem tulil kakor slon, ki dirja iz območja prihajajočih puščavskih vetrov, da so me prestrašeno zrle tope vojaške straže: Jaz, ki sem že kost in koža, ne bom umrl! Kdo je občutljivejši od mene in kdo je večji daljnovidec? Presilno je v meni brezmejno sovraštvo do vsega obstoječega in prevelika neskončna blaznost ustvarjati, o, ustvarjati iz niča! (Ko sem prenehal trepetati v svoji notranjosti, sem se pričel sukati nediplomirani inženir po svoji zvezdarni, ki sem jo zidal v obliki ogromnega daljnogleda, ob gradnji katerega sem bil trdno prepričan, da sem nehal živeti, ker sem se mudil v pokrajinah, ki jih še ni videlo nobeno človeško oko in sem ves vztre- 
petal, ko sem zagledal nevidnega klavirskega virtuoza, obdanega z angelskim zborom.) (Podbevšek, Moje ekstaze 92)

Podbevšek je pesnitev napisal leta 1919, kmalu zatem, ko se je vrnil iz vojne: "duševno in telesno pol mrtev, zraven pa še $\mathrm{v}$ samega sebe zatopljen in to skoraj preveč«, kot je 20. julija 1920 dejal v pismu Miranu Jarcu (nav. po Dović, $M o z ̌ 28) .{ }^{2} \mathrm{~V}$ nevidnem virtuozu ni težko prepoznati skladatelja, umetnostnega prevratnika in Podbevškega prijatelja Marija Kogoja, ki mu je bil Podbevšek blizu in mu je stal ob strani tudi v letih po 1930, ko je Kogoj zbolel za shizofrenijo (Vidmar, »Slovenska« 304).

Pisatelj Vladimir Bartol (1903-1967) je v petdesetih letih 20. stoletja, ko si je v nizu esejev prizadeval za rehabilitacijo Podbevška, o njem zapisal, da je po prvi svetovni vojni zablestel »kot meteor, bolje: kot zvezda repatica na slovenskem Parnasu, katere rep je tvorila cela plejada občudovalcev in posnemovalcev« (nav. po Dović, Mož 77). Med Podbevškove občudovalce je v svojih študijskih letih v Parizu (od leta 1926 do junija 1927) spadal tudi Bartol, in sicer skupaj z nekaterimi drugimi mladimi slovenskimi literati in intelektualci, med katerimi je bil tudi Josip Vidmar, ki je že tedaj slovel kot eden izmed najvplivnejših literarnih in umetnostnih kritikov na Slovenskem. Čeprav je Vidmar kljub živahnemu sodelovanju s Podbevškom in Kogojem (v sklopu "novomeške pomladi« in pri avantgardistični reviji Trije labodi; gl. Dović, "Podbevškova « 432-437) kasneje večkrat zagotovil, da sam "ni nikdar bil nikakršen avantgardist (Vidmar, "Slovenska« 302), je svoje pariške sovrstnike presenetil, da je vseeno znal cele stavke in odstavke iz zbirke Človek z bombami na pamet. In to štiri leta za tem, ko sta se $s$ Podbevškom idejno razšla (konec leta 1921). Ne glede na to pa je Vidmar v Podbevškovih pesnitvah še naprej zaznaval globoko simpatetično vez. Šlo je, tako Bartol, za »adekvatne formulacije duševnih stanj človeka moje generacije. Izražali so [...] razpoloženje človeka, ki je izšel iz prve svetovne vojne sicer ranjen in razbolen, vendar ne poražen" (Bartol 332).

Vidmar je v recenziji zbirke Človek z bombami po njenem izidu prav v tem smislu zapisal, „da ni znal razen Cankarja pri nas še nihče tako pretresljivo pokazati, kaj je vojna" (Vidmar, "A. Podbevšek" 57). O Podbevškovih pesnitvah je dejal, da »vsebujejo veliko spoznanja, [...]

\footnotetext{
${ }^{2}$ Podbevšek je bil vpoklican v avstrijsko vojsko 1 . februarja 1917. Najprej je bil na usposabljanju v Judenburgu, nakar je bil določen za soško fronto; sodeloval je v ofenzivah na reki Piave. Zbolel je za garjami in tuberkulozo; za obe bolezni se je po končani vojni zdravil v novomeški vojaški bolnišnici (Petrè 680; Dović, Mož 16).
} 
dasi ne v smislu zavednega svetovnega nazora, temveč vsak predmet je instinktivno in svojevrstno prebavljen in nekako do bistva prikazan" (Vidmar, "A. Podbevšek« 57). Fran Petrè je v Podbevškovi umetnosti prav v tem smislu prepoznal nadrealizem, ki ga je André Breton od leta 1924 zasnoval kot "psihični avtomatizem" (Petrè 689). Od tod tudi pojem ecriture automatique ali avtomatsko pisanje: $\mathrm{v}$ bistvu gre za pisanje brez miselnega nadzorstva; zavest se pomakne $\mathrm{v}$ ozadje, $\mathrm{v}$ ospredje stopijo nezavedni, sanjski in spontani elementi čutnih procesov (vizualnih in ostalih), ki so jih umetniki pretvarjali v simbole in jim tako ob umetniškem podeljevali tudi velik psihični pomen. Čeprav je Petrè domneval, da je Podbevšek »eden od predhodnikov ali začetnikov evropskega nadrealizma, in sicer brez zveze s francoskimi tvorci«, in se je na to domnevo opiral tudi Bartol (Dović, Mož 78), vsaj delno plavzibilna pa se zdi tudi Doviću, ko v navezavi na spominski zapis Milčka Komelja pravi, da "[v]saj Žolta pisma, morda pa tudi deli himen, kažejo možnost, da so bili napisani na tak način " (Dović, Mož 78), z njo ni mogoče soglašati. Prej se zdi, da napeljuje na osnovo izkustva, ki jo je implantirala vojna. Vsekakor izstopa, da se prvoosebni lirski subjekt že v Žoltih pismih (cikel pesmi je verjetno nastal konec leta 1914 ali na začetku naslednjega leta) sprašuje: "Zakaj molčim?» in odgovori: „Prevelik je bil hip, ki me je rodil in jaz premajhen tisto uro/spoznanja." (Podbevšek, Moje ekstaze 15) Tega hipa, v katerem ni težko prepoznati vdora strahot vojne v pripovedovalčevo psiho, ni bilo mogoče prevesti na razumsko oziroma simbolno raven. A vendar. »Oči, strmeče dvajseto stoletje mrličev so se začele zavedati hipnotizma mehanizma ..." (Podbevšek, Moje ekstaze 11; poudarek je moj)

Katarina Šalamun Biedrzycka sodi, da »bi lahko imeli tudi vsega Plesalca $v$ ječi [pesem je nastala 1919] za razgiban scenarij za surrealistični film" (Şalamun Biedrzycka 69), ker osnovno gradivo v njej ne predstavljajo toliko besede kot zlasti vizualne predstave oziroma "slike«. Pri tem se avtorica sklicuje na Podbevškovo lastno izjavo (iz leta 1960): "Da bi mogel svoja fantastična občutja ... izraziti, sem začel graditi z ritmiko menjajočih in podečih se predstav in idej." (v Šalamun Biedrzycka 70) Alojzij Remec je ta postopek že novembra 1920 povezoval s tem, kar je Podbevšek imenoval "godbo v valovih«: "Zavrača povečini ritem in rime po dosedanjih vzorcih in izkuša z ritmiko predstav in občutij. [...] Vrsti se pred nami vtis za vtisom, primera za primero, vizija za vizijo. [...] Mesto živega filma vidimo skioptične slike, ki jih moramo sami vezati [...] [ker] so dozdaj še prerahlo nanizane druga ob drugi.» (Remec 2) Šalamun Biedrzicka nekaj takšnih »slik« na meji sanj in resničnosti tudi našteje: 
zatisnjene oči, rdeča roža v črnih laseh, kačje telo, zamreženo okno, mlado življenje, okrvavljen mladič, sveži zrak, prestreljena glava, presunljivo jokanje, pretresljiva prošnja, sivi starčki, vitke žene, zlati prestol, voščene sveče, zrela pšenična polja, pridne žanjice, brezskrbna mladost, živa pripovedka, otožni glasovi, pozne večerne ure, bleda mesečina, srebrne strune, mogočen slap, nebeške zvezde itd. (Šalamun Biedrzicka 70)

Ni naključje, da je tudi Breton, ki mu ne gre oporekati primata - ali ob Ivanu Gollu vsaj soprimata (prim. Vrečko, Srečko Kosovel 466) izumljanja "nadrealizma«, ta postopek začel razvijati prav v času vojne. Kot sanitetnik je delal v lazaretu, kjer je s pomočjo Freudovega koncepta prostih asociacij prisluhnil pripovedim travmatiziranih vojakov. Zelo pomembni za Bretonovo lastno pesniško pot so bili sestanki s francoskim literatom Apollinairom, ki je leta 1917 prvi uporabil izraz "nadrealizem« (Becker) - leta 1916 je bil ranjen v glavo, od česar si ni nikoli povsem opomogel, ob koncu vojne pa ga je pokosila epidemija španske gripe.

\section{Podbevšek: začetnik slovenskih zgodovinskih avantgard in njegovo/njihovo razmerje do futurizma}

Anton Podbevšek velja za začetnika in hkrati osrednjega predstavnika prve faze slovenskih zgodovinskih avantgard. ${ }^{3}$ Kot vse evropske zgodovinske avantgarde je treba tudi slovensko zgodovinsko avantgardo vrednotiti kot "ansambel skupinskih gibanj in izmov« (Fähnders 6), katerih začetki sovpadajo z italijanskim futurizmom in še določneje $s$ Futurističnim manifestom, ki ga je leta 1909 izdal njegov spiritus agens Filippo Tommaso Marinetti. Vrečko slovensko avantgardno gibanje povezuje z "labodovci«, "pilotovci«, "konstrukteristi«, "konsisti« in "tankisti« (Vrečko, "Labodovci« 52). Že samo dejstvo, da so se avantgardisti združevali $\mathrm{v}$ skupine in skupinice, je bilo $\mathrm{v}$ popolnem nasprotju z dotedanjim osebnim pristopom do umetnosti. To velja tudi za italijanski futurizem, ki je iniciiral prevratniški ideal radikalnega preloma z vsem preteklim. Marinetti je v manifestu izpostavil naslednje

${ }^{3}$ Druga faza slovenske zgodovinske avantgarde (1925 do 1929) je dosegla svoj vrhunec v izdaji treh številk revije TANK (1927). Ta faza je imela likovno-gledališki pečat. Njena glavna protagonista sta bila Avgust Černigoj in Ferdo Delak. Srečko Kosovel zavzema nekakšno vmesno pozicijo, saj ga ni mogoče prišteti ne k prvi in ne $\mathrm{k}$ drugi fazi, poleg tega so bile njegove konstruktivistične pesmi objavljene šele po njegovi smrti (Dović, "Slovenska« 298-299; Vrečko, Srečko). 
osnovne postavke futurizma: prelom $s$ tradicionalno kulturo in estetiko, slavljenje moči, hitrosti, mladosti, moškosti, tehnike, nacionalizma in vojne.

Futurizem je že pred prvo svetovno vojno iz Italije prodrl tudi v slovenski prostor. Že od leta 1909 so o njem poročale številne slovenske kulturne revije. O preporodovcih, članih tajnega narodnorevolucionarnega dijaško-študentskega gibanja, zbranih okoli mesečnika Preporod, je Lino Legiša zapisal, da izpričujejo sorodstvo s futurizmom. Njihov program se je zavzemal za padec Avstrije in za zedinjenje južnih Slovanov. Juš Kozak, ki se jim je kot kladivar (član vodilne peterice) pridružil ob začetku leta 1913, govori v spisu Problem Slovenstva o nuji prevlade moške energije, o idealu očiščevalnega ognja, o zaničevanju ženske. »Vse to poudarjanje pa gotovo ne poganja naravnost ali vsaj ne samo iz Nietzscheja, ampak se že hrani iz sočasne, precej bližnje oživitve v futurizmu." (Legiša, "V ekspresionizem « 15) Ob nespregledljivi fascinaciji pa je futurizem med slovenskimi intelektualci in avantgardisti vzbujal tudi skepso in odpor.

Bistveni razlog za odpor do futurizma je bil v tem, da se je ogreval za italijanski iredentizem, ki je v svojem kontinuiranem odnosu z imperializmom, prepojenim s principi nacionalnih teženj "neodrešenih dežel« (terre irredente), spodbudil ne le vojno proti Avstro-Ogrski, temveč tudi vznik obmejnega fašizma. Mesto Trst je v tem sklopu predstavljalo pomembno strateško točko. Marinetti je v Trstu uzrl »futuristično mesto par excellence (Pizzi 113; Toporišič 2). Ko je govoril o njem, je povezal futurizem in iredentizem ter obema "vdahnil« slutnjo vojne in nasilja. Prvo futuristično serato, ki je 12. januarja 1910 potekala v tržaškem gledališču Rossetti, je takole najavil: "Il nostro treno corre verso Trieste, rossa polveriera d'Italia (Naš vlak drvi proti Trstu, rdečemu smodniku Italije).«(Marinetti, »Rapporto« 9) Leta 1915 je v zaključnem poglavju knjige Guerra sola igiene del mondo (Vojna, edina higiena sveta) zapisal: "Da bi vzbudili odpor proti trozvezi in simpatije do iredentizma, smo futuristično gibanje začeli v Trstu, mestu, v katerem smo imeli čast, da izpeljemo našo prvo serato [...]. Našo drugo serato (Milano - Teatro Lirico - 15. februarja 1910) smo zaključili z vzkliki: Naj živi vojna, edina higinea sveta!« (Marinetti, Guerra 151)

Zaradi tega ne preseneča, da so literarni časopisi in revije v Ljubljani že $\mathrm{v}$ času prve svetovne vojne prenehali s poročanjem in informiranjem o italijanskem futurizmu (Toporišič 5). Kar naenkrat, še zlasti pa po 13. juliju 1920, ko je $s$ požigom Narodnega doma, osrednjega simbola Slovanov in Slovencev v Trstu, val fašističnega nasilja zajel še vso Primorsko in Istro, se je zdelo, da futurizem ne predstavlja več navdiha 
za slovensko umetnost, še več, postal je pravšnja tabu tema. To velja še zlasti za tiste umetnike, ki so leta 1918 proti svoji volji postali italijanski državljani. Kadar je Kosovel omenjal futurizem, je to storil le bežno (Vrečko, Srečko 185) in zaman bi iskali globljo vsebinsko ali formalno sorodnost med futuristično pesniško prakso in njegovimi konsi (Troha 9, 11). Tankočutno se je Kosovel odzival na italijansko zasedbo krajev, kjer se je rodil in doraščal, in postal »eden najpoglavitnejših navdihovalcev generacije, ki se je pripravljala na spoprijem s črno diktaturo« (Pahor 11; Jurić Pahor, Memorija 270-306).

Tudi oba vodilna protagonista druge faze slovenske zgodovinske avantgarde Avgust Černigoj in Ferdo Delak, prvi po rodu Tržačan, drugi Goričan, sta se začela odmikati od idej in praks futuristične umetnosti, čemur so prav tako botrovale povezave futurizma $s$ fašizmom (Toporišič 16). Obrnila sta se v smer ruskega konstruktivizma, ki ga je Černigoj pobliže spoznal spomladi 1924 na Bauhausu v Weimarju. Oklenila sta se tudi zenitizma, jugoslovanskega avantgardnega gibanja, katerega nastanek in razvoj sta bila vezana na časopis Zenit (od 1921 do maja 1923 je izhajal v Zagrebu in nato do 1926 v Beogradu), iz prepričanja, da lahko predstavlja "protiutež futuristično-fašističnim predstavam o italijanski superiornosti nad balkansko kulturo" (Toporišič 12). Sprejemala sta tudi zenitistično zamisel »balkanskega barbarogenija«, ki bo propadli kulturi Zahodne Evrope prinesel dinamizem, svežo moč Vzhoda (Pranjić 140-141). Ljubomir Micić, glavni protagonist zenitizma, je to kategorijo potreboval, da bi se z njo jasno razločeval od Marinettija, avtorja futuristične predstave barbarstva - čeprav mu je hkrati hotel biti podoben (Kralj 34).

Nekaj analognega velja tudi za Černigoja in Delaka, ki sta kljub skeptičnemu odnosu do futurističnega angažmaja znotraj fašistične Italije "hkrati vseeno ali temu navkljub ohranjala liaisons dangereuses $s$ futurizmom " (Toporišič 17). Peter Krečič, dober poznavalec Černigojevega opusa, smatra Černigoja celo kot "neke vrste slovenskega pendanta Marinettiju“ (Balantič). Obe številki revije TANK, ki ju je leta 1927 v sodelovanju s Černigojem uredil Delak, ne skrivata tesnega sorodstva z Micićevim zenitizmom in Marinettijevim futurizmom: »Tank je pojem zdrave sile, kraj, kjer izhaja pa priča, da se balkanska narava vedno bolj razvija in zaveda svoje funkcije. [...] Ljubljana mora postati 'garage' svetovne drveče lepote. To je parola balkanske narave." (Delak, "Mladina" 5) Citat daje slutiti, da tudi slovenski avantgardisti niso bili izvzeti iz splošnega modela zmagovitega nacionalizma, ki je v tem primeru predvideval sprevračanje hierarhiziranega razmerja od domnevno

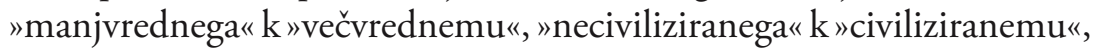


"perifernega« $\mathrm{k}$ »osrednjemu«, v vsakem primeru pa $\mathrm{k}$ mitu tipa »Biti hočemo barbaro-geni« (Delak, »Mi« 69). Tudi Kosovel je najprej sledil temu mitu, vendar je bil ta značilen za njegovo destruktivno pesniško fazo. Od aprila 1925 je Kosovel sprejel pojem barbarstva zunaj futurističnih in zenitističnih kontekstov ter začel uveljavljati izrazito politično razumevanje tega pojma, povezanega $s$ fašistično ogroženostjo primorskih Slovencev (Vrečko, »Barbarogenij« 265-7).

Čeprav se slovenski literarni zgodovinarji nagibajo k predpostavki, da se je Podbevšek na začetku svoje pesniške poti navduševal nad futurizmom in da ga je pod futurističnim vplivom vojna "magično pritegovala" (Dović, "Podbevšek in Cvelbar "238; Dović, Mož 24; Poniž, "Sedem desetletij« 15, 19), se vendarle zdi, da je bil njegov odnos do futurizma in vojne od vsega začetka odklonilen, ne pa šele od njegove vojaške izkušnje od februarja 1917 dalje. Po Veri Troha se je Podbevšek futurističnemu občutju sveta približal edinole v dveh pesmih iz cikla $O$ pilotu zrakoplovu št. ..., in sicer $N a$ vožnji in Večer v velikem mestu, kjer so pojmi iz "futurističnega arzenala" uporabljeni zato, da reproducirajo "dinamiko dogajanja" (Troha 102). Toda že v Podbevškovih Žoltih pismih, ki veljajo za "uradni začetek slovenske zgodovinske avantgarde" (Vrečko, "Labodovci« 50) in za "najočitnejši primer vpliva futurizma na slovensko pesništvo « (Antončič 66), je prva svetovna vojna prisotna kot katastrofična slutnja o koncu sveta, kot nenehni »me ... men ... to ... mo ... ri« (Podbevšek, Moje ekstaze 13). Prvoosebnega liričnega subjekta prevzema »nervozen: i ... a ... i ... a a in draži »skoro vedno histerični: hi ... hi ... hi ... hi«, civilizacija »mrzlo povdarja: kra ... kra ... kra ... kra«, "trop krakajočih vranov« objokuje žive in mrtve (13). Rima, ki praviloma označuje ujemanje glasov na koncu verzov, se pri Podbevšku ne izteka v konsonanco, temveč v disonanco, ki sozvočje groteskno zrelativizira ali izniči, kot na primer: "Moja moč in volja / te pozdravlja in pošiljam ti zadnji pozdrav z bojnega polja ... (19)

V Žoltih pismih Podbevšek vojne ni - kot je to storil futurizem pozdravil kot tisti »očiščevalni dogodek, ki bo šibko in nedozorelo, staro in trhlo pometel, ostalo bo samo življenjsko, krepko, trdno, čvrsto" (Poniž, "Slovenske« 171). Prav tako v njih ne opeva militantnih lastnosti, ki so bile Marinettiju »svete" (agresivni tok, brzi korak, smeli skok, krepka dlan, silna pest), prav nasprotno, osredotoča se na človekovo notranjo stisko, izpostavljenost in tesnobo. Ritem Žoltih pisem je rezek, odsekan, jezik spominja na "govorico travme" (Jurić Pahor, »Narativnost" 165-170): stavki in besede so razbiti, sintaksa delno porušena. Travme praviloma povzročajo dogodki, ki so zunaj običajnega, privajenega človekovega izkustvenega in predstavnega sveta ter 
zato preplavijo in uničijo njegov varovalni sistem, kamor velja prišteti tudi jezik, s katerim razume in obvladuje situacije. Ingeborg Bachmann je že glede na predvojno moderno poetiko ugotovila: "Zaupno razmerje med Jazom in jezikom in stvarjo je močno zrahljano." (Bachmann 12) Če tradicionalni lirični jezik ni več zadoščal za opis modernega sveta predvojnega časa, bi moralo to toliko bolj veljati za prikaz vojnega časa. Resničnost vojne, ki je bila živa še dolgo po vojni, je avantgardistične pesnike prav izzivala, da nadaljujejo s svojimi jezikovnimi eksperimenti, jih razširjajo, hkrati pa jih je silila v molk (Rehage 30-31). O svojih ustvarjalnih dneh je Podbevšek Miranu Jarcu 24. julija 1919 pisal, da je ves v »svetosti dela«, "da bije bitko ob Marni« in hodi »ob nočnih urah v gozd« ter se »razgovarja z duhovi«. Napoveduje pa mu tudi svoj veliki prodor, ki živo predočuje prav dvorezno dinamiko molka: „Ob priliki odprem vse svoje zatvornice in takrat te oškodujem za svoje skrivnostno vodino molčanje, takrat ko se zadrvim spenjen čez mlinska kolesa." (Dović, Mož 19)

\section{Odnos Podbevška in slovenskih kulturnih in literarnih ustvarjalcev do futurističnega pojmovanja »domoljubja»}

Žolta pisma skupaj z dopisom, ki ga je šestnajstletni Podbevšek 7. marca 1915 poslal uredniku Ljubljanskega zvona Šlebingerju, Vrečko označuje za "protomanifest" slovenske avantgarde (Vrečko, "Labodovci« 50). $\mathrm{V}$ dopisu pove, da pripada »najmodernejši struji«, svojo poezijo utemeljuje kot plod dolgega študija »raznih meditacij potrpežljivih asces in sugestij «, ki se izpričujejo zlasti v jezikovnih inovacijah, kot so odsotnost ločil, "stavkov z 'da' in veznikov kakor, po v na pri za i.t.d." ali "prosto tekoč verz in anarhija stopic« (Podbevšek, Moje ekstaze op. ur. 9). Verjetno si je Podbevšek obetal objavo svoje pesnitve. Že od leta 1910 je v Ljubljanskem zvonu objavljal svoje pesmi Anton Debeljak, takrat najbolj vnet propagator futurizma na Slovenskem, leta 1912 je $\mathrm{v}$ tem listu priobčil tudi razpravo Paseizem in futurizem in izpostavil "strastno narodnjaštvo" futuristov (Troha 94, 100). Mogoče pa je treba prav v pomanjkanju te "strasti« iskati razlog, da je Šlebinger Žolta pisma zavrnil. Podbevšku je odpisal, da ima "'najmodernejša struja' brezdvomno mnogo zdravega v sebi«, vendar njegova pesnitev ni »žnjo v nikakem sorodstvu«. V pesnitvi je urednik zaznal le »apokaliptično megleno vsebino" ter "nevaren" in "nesramen " poskus »bagateliziranja jezika«. Šlebinger je tudi prvi, ki Podbevšku pove, da takšna poezija sodi v »delokrog psihijatra in ne esteta« (Podbevšek, Moje ekstaze op. ur. 11). 
Kaže, da je Podbevšek že v Žoltih pismih pristal na ločitev narodne ideologije in literature (Vrečko, »Labodovci« 53), ki so jo tik pred prvo svetovno vojno, med njo in po njej zagovarjali nasprotniki vojne in z njo povezanega imperializma. Večina teh »kritičnih duhov« ni mogla razumeti, „čemu služijo dejanja, za katera se govori, da so bila storjena za domovino" (Friedell 10). Podbevšek v Žoltih pismih »domovino" konotira s »kislim propelerjem" (Podbevšek, Moje ekstaze 9), kar pa ni v soglasju z italijanskim futurizmom - ne le zaradi nedopustne analogije med oznako kisel in oznako propeler, temveč tudi zaradi kritike "domoljubja« in vojne. Antončič ugotavlja, da je Podbevšek po zavrnitvi Žoltih pisem Šlebingerju približno dva meseca kasneje poslal še dve pesmi, Rdečo cesto in $V$ vlaku, ki izstopata z vojno tematiko in v katerih "ni več nič futurističnega» in, kot bi bilo mogoče dodati, nič nacionalističnega. Prav nasprotno, pesmi predstavljata »izrazit dokument disociacije subjekta, občutja izničenja človeka« (Antončič 70-71). Tudi ti dve pesmi sta ostali neobjavljeni. Je pa bila objavljena pesem $O b$ dnevu vpoklica na kolodvoru, ki tematsko, slogovno in po času nastanka spada v isto obdobje. Pesem, ki je prvič izšla 1919 v Domu in svetu, tematizira ganljiv in presunljiv prizor slovesa; za štiriglasni moški zbor jo je uglasbil Kogoj. Kot je predvidel že urednik Stelè, je pesem kmalu dosegla antologijsko vrednost (Podbevšek, Moje ekstaze op. ur. 72). Vse tri v tem odstavku omenjene pesmi izstopajo tudi po tem, da prvoosebni lirski subjekt v njih ni prisoten oziroma je to kvečjemu kot pripovedovalec. Šele po Podbevškovi izkušnji fronte 1917-1918 se združita prvoosebni avtorski lirski subjekt in tema vojne (Antončič 74).

To se prvič zgodi v pesmi Izumitelj na zemlji. Gre torej za prvo Podbevškovo pesem, ki jo določa osebna izkušnja vojne: „V njej trpi posameznik sam, medtem ko kasneje v Plesalcu v ječi trpijo množice." (Antončič 79) Tukaj se razodeva namera, ki jo je Philipp Rehage zaznal tudi pri avantgardističnih pesnikih, kot so Apollinaire, August Stramm, Wilhelm Klemm in zelo eksplicitno Jean Cocteau, da se ob lastnem da glas tudi številnim anonimnim žrtvam vojne (Rehage 248). Od tod izvira po Rehageju tudi zelo kritična do agresivna drža teh avtorjev v primerjavi s konvencionalno, klišejsko vojno liriko, ki hkrati pojasnjuje, kako velik eksistencialni pomen je zanje imelo iskanje po adekvatnem prikazu doživete groze. Opažanje Rehageja potrjuje ob Plesalcu v ječi tudi Podbevškova pesem Carovnik iz pekla. Obe pesmi imata posvetilo tovarišu iz vojne. Prva je posvečena "veseljaškemu, samo za motorje vnetemu prijatelju Cirilu Justinu«, druga pa za špansko boleznijo umrlemu tovarišsu Janku Starcu. Pesnitvi potekata v obliki dialogiziranega spominjanja, prepredenega $\mathrm{z}$ ubeseditvijo psiholoških in eksistencial- 
nih stanj človeka, ki je izpostavljen mašineriji vojne. Mehanizem, ki je tu na delu, je vedno povezan $s$ telo zaznavajočimi predeli ali s telesom povezanimi potmi, ki prenašajo signale $\mathrm{v}$ telo in iz njega (Podbevšek, Moje ekstaze 84-88).

Podbevšek je s pesmima Plesalec $v$ ječi in Čarovnik iz pekla izkazal odmik od svojega lastnega literarnega oblikovanja. Obe pesmi, ki sta po navedbah Podbevška nastali leta 1919 (Poniž, "Sedem« 22), sta do te mere prozificirani, da ju Poniž označuje kot "ritmizirano prozo« (22), Kocijan pa kot kratko pripovedno prozo (Kocijan 45; op. 12). Petrè se težiščno nanaša prav na omenjeni pesmi in poudari, da je Podbevšek z njima ustvaril "povsem nov sistem pisanja", s katerim je "hotel ujeti tisto drugo realnost, stvarnost duševnih stanj $\mathrm{v}$ čim bolj nedotaknjeni, nespremenjeni resničnosti« (Petrè 688-689). In ta stvarnost je dosledno vezana na vojno izkušnjo. Da bi se ji Podbevšek čim bolj približal, preoblikuje metafore čustvene romantike z novimi, povsem nečustvenimi nosilci (tehnika, prometna sredstva, industrija, vojaška stroka) (Čeh Steger 98). Na ta proces kažejo tudi pridevki "ledeno srce«, "dinamitne misli«, "steklene oči«, "orjaška sila«. Ali pa ugotovitev Huga Balla, utemeljitelja dadaizma, da so v vojni »ljudi zamenjali s stroji« (Ball 34). Iz najhujše bivanjske groze se v Čarovniku iz pekla porodijo "rdeče kompozicije«, najbolj boleče in najbolj intenzivne, ki jih do popolnosti razume tudi prestrašeni bojni tovariš (Čeh Steger 98). V Plesalcu $v$ ječi se značilno futuristično navdušenje nad tehniko, ki je prisotno še v posvetilu "za motorje vnetemu prijatelju«, prevesi v zgroženost nad množično morijo, ki jo terja "totalna« industrijska vojna. Podbevšek jo med drugim ponazori z alegorično podobo žanjice Smrti, ki jo poveže z metaforami strelskega ognja in vulkanov: pokrajine gorijo, deflagirajo, detonirajo, najmanjši košček zemlje se zdi, kot da bo začel vsak čas bruhati. Hkrati pa tudi ta pesem popelje v sublimne prostore, ki kaj lahko vzniknejo, ko je subjekt soočen $\mathrm{z}$ "nepopisljivo grozo«, mu pomagajo najti izhod iz stiske: pripovedovalec hodi proti "bajkepolnim goram", sliši zvok violine, pastirja, ki igra na piščalko, uničujoči strelski ogenj se pretvori $\mathrm{v}$ raznorodne prizore in prikazni, v zahajajočo svetlobo, lok »blede mesečine«, ki se zdi kot odrešujoča "nebeška harfa«: in je "potegnil z roko prek srebrnih strun", da so ga »omamljali prelepi glasovi do nezavesti«. ( $\mathrm{Za}$ večplastno interpretacijo obeh pesnitev ter pojav sublimnega gl. Jurić Pahor, Memorija 231-238, 133-135.)

Izrecno distanco do futurizma je Podbevšek izrazil 29. maja 1919 v pismu Božidarju Jakcu, v katerem se huduje nad Miroslavom Krležo, da je sprejel v objavo pesem Frana Albrehta Iz bojnih ritmov. Pesem se 
mu je zdela "malo manj kot dobesedni plagiat laških futuristov in takih drekačev“ (Dović, Mož 21). Albreht v njej brez zavor ubeseduje nov, kolektivni etos (»Zdravstvujte mi, bratje zavrženi, nemi«; Albreht 74). Ta pesem, ki jo je, se zdi, rahlo razširil in uvrstil v cikel Bojni ritmi, v drugi kitici skorajda dobesedno govori o »izstopanju iz sebe«, iz »jaza«, ki ni več "jaz«, v »mi«, vključuje tudi pesniško formulacijo, ki zahteva obračun z nietzschejanskim solipsizmom: "Jaz zaničujem te, srepooki, / vase zamaknjeni kritik, / ko z glorijo venčan kavarniških dimov / s kačjo lokavostjo, s plehko gizdavostjo se razkazuješ v svojem ornatu: / stopi iz sebe! Stopi iz sebe!" (Nav. po Kos, „Šorli« 332) Čeprav se je v "srepookem, vase zamaknjenem kritiku" prepoznal Josip Vidmar (Kos, „Šorli« 332), bi bila ost kaj lahko naperjena tudi proti Podbevšku, še zlasti, ker je njegov lirski subjekt "ves čas obrnjen navznoter (Antončič 90), v hojo po notranjih krajinah, ki jih, kot domneva v Carovniku iz pekla, »še ni videlo nobeno človeško oko«. Podbevškov lirski subjekt ostaja vseskozi "oseben, avtorski, predvsem pa v svojem ustvarjanju absoluten" (Antončič 88). V tem smislu mu je tuja tudi Marinettijeva programska zahteva (11. točka Tehničnega manifesta) po uničenju jaza $\mathrm{v}$ literaturi in s tem vse psihologije.

"Sebe samega je videl, nas ne, in to v času, ki je klical ves po človeku«, je Podbevšku leta 1925 očital France Vodnik v Domu in svetu (Vodnik 256). Po njegovem se je Podbevšek oddaljil od »bistva slovenskega človeka"s tem, da je »kopiral Nietzschejevega Herrenmenscha". Svet, ki se pri Podbevšku odgrinja, je, tako Vodnik, svet vase obrnjenega, sebičnega duha - svet "človeko-boga«, ki poje samemu sebi, "a ne človeštvu" (256). Podobno so se tudi nekdanji Podbevškovi učenci (Vladimir Premru, France Onič in Bartol Stante) - po besedah Vodnika - odvrnili od »evangelija, ki ga nam oznanja ta zapozneli 'brat' Zarathustre» (256; glej tudi Dović, "Podbevškova« 431-432). Položaj, ki je nastal v letih po prvi svetovni vojni, je bil tudi na Slovenskem takšen, da "prvotnega«, "spontanega" sprejemanja Nietzschejeve misli ni več dopuščal (Kos, „Šorli« 332). Ali kot je zapisal Hugo Ball: „Čas je besno stremel za tem, da izsledi vse posebno, individualno, da bi ju kot oviro odstranil." (Ball 14) Albrehtova »futuristična« pesem $I z$ "Bojnih ritmov" se že aprila 1919 zaključuje: »Mi nismo odtód. Mi smo rušitelji / vsega kar je: - kar uklepa srcé, / duhá in teló ... Zato smo stvaritelji. / Mi smo graditelji / Bodočnosti.« (Albreht 74)

Že od leta 1921 tudi "najmlajši» avantgardisti, med njimi omenjena trojica, Podbevšku niso več sledili »na poteh razdrapanega individualizma«, kot se je izrazil eden njegovih prvih proučevalcev Petrè (Petrè 691). Tirade proti Podbevšku in njegovi umetnosti so se vrstile. 
Označevali so ga/jo kot nekaj, kar ni (duševno) zdravo, ${ }^{4}$ krepko in produktivno, temveč je patološko, afektirano, kameleonsko, di/sociirano in posledično nekaj škodljivega, radikalno drug/ačn/ega, nepripadnega (Jurić Pahor, Memorija 251-258). Najmlajša Premrujeva struja je Podbevšku atestirala celo »jako žalosten finis finalis« (Dović, Mož 54). Njenemu videnju, da je Podbevškovo ustvarjanje "sramotna pega na kulturi slovenskega naroda in na kulturi človeštva sploh" (Dović, Mož 54), se je leta 1925 pridružil tudi Vidmar, ko je potrdil stališče svojega kolege Albrehta, "da se nikjer na svetu ne piše več taka 'poezija' à la Podbevšek" (Vidmar, "Urednikov« 3). Svojo uvodno besedo, ki v bistvu postavi družbeno/narodno represijo nad literaturo, Vidmar zaključuje tako:

Zato bomo skušali s trdovratnim in nasilnim - zakaj vsaka resnica silo trpi in le nasilni si jo vzame $-\mathrm{s}$ trdovratnim zasledovanjem in izsledovanjem resnice, samo ene resnice, ki je skrita $\mathrm{v}$ pristnosti umetnin in $\mathrm{v}$ njihovi umetnostni pomembnosti /.../ skušali doseči dvoje: urediti duha javnega mnenja, ozdraviti in razviti občinstvu okus za pravo, sebe pa z neprestanim opazovanjem pravega vzgojiti in pripraviti na prihod tistega pojava v naši kulturi, ki ga duh naroda tako težko in nemirno pričakuje. (3)

Vidmar ni navedel, da je Albreht ob izjavi, da se nikjer več ne piše poezija à la Podbevšek, slednjega označil celo za epigona, njegove pesnitve pa je - ustrezno tedanjemu antisemitskemu cajtgajstu - povezoval $\mathrm{z}$ "židovsko nemško vizionarnostjo« (Jarc 3). Miran Jarc, Podbevškov sošolec, prijatelj in pisatelj, $\mathrm{k}$ tem predpostavkam, ki tudi njemu niso prizanašale, pripominja, da Albreht sodobne poezije očitno ne pozna in da mu je neznano morda tudi, da je »knjiga knjig Sveto pismo - hebrejskega izvora!«. Ob oznaki »epigon« za Podbevška je dejal: »Nasmehniti se moram tej besedi, če jo vidim v zvezi s Podbevškovim imenom. Ne vem za človeka, ki bi bil tako strasten v zvestobi do samega sebe in tako pretresljivo resen v izražanju samega sebe." (3) Ob izidu zbirke Človek z bombami se Jarcu zapiše: "Smešno se je prepirati o tem, ali ima ta 'oblika' bodočnost ali ne. Važno je, da jo je rodil človek, ki je dal najtočnejši in najadekvatnejši odmev tej dobi [vojne groze].«(3)

${ }^{4}$ Ugledni slovenski psihiater Alfred Šerko je Podbevška leta 1920 z neprikritim rasizmom ("psihopatični, polblazni tip človeške pasme") pošiljal celo v sanatorij (Dović, Mož 35). Nedvomno pa Šerkovo stališče ni segalo "v skrivnosten, za umetniško ustvarjanje tako ploden svet podzavesti, s katerim se je že takrat ukvarjala psihoanaliza» (Mušič 165-166). 


\section{Zaključek}

Članek na primeru slovenske zgodovinske avantgarde, še zlasti Antona Podbevška, ki je v slovenski prostor prvič vpeljal model "pisateljaavantgardista" (Dović, "Podbevškova» 427), ponazarja, kako se je izkušnja prve svetovne vojne vpisovala $\mathrm{v}$ njihovo umetnost in $\mathrm{v}$ njihove umetniške prakse. Zagovarja predpostavko, da se Podbevšek nad vojno nikdar ni navduševal, za razliko od nekaterih drugih avantgardistov (Delak, Černigoj) in/ali »graditeljev Bodočnosti« (Kozak, Albreht) mu je bila od vsega začetka tuja tudi militantna, $\mathrm{z}$ imperialističnimi in nacionalističnimi aspiracijami prežeta retorika italijanskih futuristov. Že na svojem velikem ljubljanskem nastopu v Mestnem domu 12. septembra 1921 je Podbevšek poudaril, da so "novi umetniki pacifisti«, "nacionalizem pa zastarela oblika, ki jo je treba premagati« (L.[ah] 2). Uprl se je "nacionalni rabi literature v ideološke namene" (Vrečko, "Labodovci« 54) in s tem zadel ob vse tisto, kar je tradiciji veljalo za lepo, razumno, logično, zdravo, naciotvorno itd., in zato doživel oceno, da njegovo delo sodi v delokrog psihiatra in ne esteta. Nič samovoljnega, ambivalentnega, fantastičnega ali bombastičnega naj ne bi bilo več v pesnitvah, še zlasti pa je veljalo iz njih pregnati spomin vojne v njenih travmatičnih razsežnostih. Članek analizira tudi frontovsko držo napram "vsemu ekspresivnemu in vsakršni eruptivni pristnosti « (Lethen 111), ki je naposled zadela tudi »baržunasto liriko«, kot je Kosovel označeval svoje zgodnje pesmi. Literatura bi se morala prilegati "organski konstrukciji» (Vrečko, Srečko 129-145) naroda, hkrati pa jo je veljalo povezati s simboli upornosti in občečloveške izpostavljenosti, kakor jih je na Slovenskem izzival italijanski fašizem. Kosovel in nosilci druge faze slovenske zgodovinske avantgarde ne izhajajo po naključju zlasti iz Primorske. Anton Ocvirk, ki je spadal v najožji krog Kosovelovih prijateljev (postal je tudi varuh njegove zapuščine), je leta 1929 - s pogledom na literaturo à la Podbevšek - takole opredelil prihodnjo pesniško usmeritev: "Iz analitičnih razkrajanj čustvenega sveta in duševnih kriz povojnih let se bo moral novi pesnik, očiščen vseh slabih sokov in gnilih primesi notranjih katastrof, polagoma dvigniti do svojevrstnega novega, izrazno in vsebinsko resničnejšega oblikovanja življenja." (Ocvirk 707) Podbevšku in literarni avantgardi prvega vala je med drugim očital, da je težila »za nejasno simbolno fantastiko, bledim poantiranjem in igračkanjem brez notranje nujnosti« (Ocvirk 707). O tem, da je bilo kvečjemu nasprotno, priča dejstvo, da Podbevšek v drugi fazi zgodovinske avantgarde, ki jo simbolizira revija Tank, ni bil resno upoštevan; bil je »de facto 'zbrisani'« (Dović, »Podbevškova" 
438). A vendar je, za razliko od "tankistov«, ki so ostali v tedanji slovenski publicistiki "popolnoma brez odmeva«, uspel dregniti »v središčni živec slovenskega kulturnega prostora" (Dović, „Podbevškova» 439), podobno kot bo to dobrih 40 let po svoji smrti uspelo Kosovelu s svojimi Integrali '26 (konsi). Leta 1967 jih je z obsežno uvodno študijo objavil Ocvirk in s tem usmeril pozornost tako na "staro" kot na porajajočo se "neoavantgardno« slovensko umetnost. Tako Podbevškov kot Kosovelov glas segata močno tudi v današnji čas: kot naracija, ki vsakič po svoje - kaže na destabilizacijo identitete v skrajno nasilnih kontekstih in, povezano s tem, na težnjo po njeni konsolidaciji in moči.

\section{LITERATURA}

Albreht, Fran (psevd. Studen, Marko): Iz 'Bojnih ritmov'«. Svoboda 1.4 (1919): 74.

Antončič, Emica. Anton Podbevšek in njegova vloga v razvoju slovenske moderne književnosti. Maribor: Obzorja, 2000.

Bachmann, Ingeborg. Frankfurter Vorlesungen. Probleme der zeitgenössischen Dichtung. München: Piper, 1980.

Balantič, Polona. "Futurizem pri nas ali lučni žarki niso bliskali z gradu - Intervju s Petrom Krečičem«. MMC RTV SLO (25. 2. 2009). Splet. 14. 3. 2021. <https:// www.rtvslo.si/kultura/drugo/futurizem-pri-nas-ali-lucni-zarki-niso-bliskali-z-gradu/158288/>.

Ball, Hugo. Die Flucht aus der Zeit. München, Leipzig: Verlag von Duncker \& Humblot, 1927.

Bartol, Vladimir. Mladost pri Svetem Ivanu: Svet pravljic in čarovnije. Prva knjiga. Ljubljana: Sanje, 2003.

Baumgarth, Christa. Geschichte des Futurismus. Hamburg: Rowohlt, 1966.

Becker, Annette. »The Avant-Garde, Madness and the Great War«. Journal of Contemporary History 35.1 (2000): 71-84.

Bürger, Peter. Theory of the Avant-Garde. Minneapolis: University of Minnesota, 1984.

Čeh Steger, Jožica. Ekspresionistična stilna paradigma v kratki pripovedni prozi 1914 1933. Maribor: Filozofska fakulteta, Mednarodna založba Oddelka za slovanske jezike in književnosti, 2010.

Debeljak, Anton. »Paseizem in futurizem«. Ljubljanski zvon 32.2 (1912): 129-134.

Delak, Ferdo. »Mladina, podaj se v borbo«. Tank 1.1 (1927): 5.

Delak, Ferdo. "Mi«. Tank 1.2. (1927): 69.

Dović, Marijan. »Podbevšek in Cvelbar«. Slavistična revija 50.2 (2002): 233-249.

Dović, Marijan. Možz bombami. Anton Podbevšek in slovenska zgodovinska avantgarda. Ljubljana; Novo mesto: Založba ZRC, ZRC SAZU; Založba Goga, 2009.

Dović, Marijan. »Slovenska zgodovinska avantgarda med kozmopolitizmom in perifernostjo. V: Marko Juvan (ur.): Svetovne književnosti in obrobja, (Studia litteraria). Ljubljana: Založba ZRC, ZRC SAZU, 2012. 297-320.

Dović, Marijan. "Podbevškova pesniška šola, Trije labodje in zaton 'bombaša'«. Slavistična revija 68.3 (2020): 427-440.

Fähnders, Walter. Avantgarde und Moderne 1890-1933. Stuttgart; Weimar: Verlag J. B. Metzler, 2010. 
Friedell, Egon. Kulturgeschichte der Neuzeit. München: DTV, 1993.

Gruden, Ivan. »L'Italia futurista". Dom in svet 26.9 (1913): 333-337 [1. del].

Jarc, Miran. »Anton Podbevšek: Človek z bombami«. Slovenski narod 1. 3. 1925: 3.

Jurić Pahor, Marija. »Narativnost spominjanja: vpogledi v avto/biografsko usmerjeno raziskovanje in v govorico ekstremne travme". Avtobiografski diskurz: teorija in praksa avtobiografije v literarni vedi, humanistiki in družboslovju. Ur. Alenka Koron in Andrej Leben. Ljubljana: ZRC, ZRC SAZU (Studia litteraria), 2011. 161-173.

Jurić Pahor, Marija. Memorija vojne. Soška fronta v spominski literaturi vojakov in civilistov. Celovec; Ljubljana; Dunaj: Mohorjeva, 2019.

Kimovec, Fran. »Kogojev koncert 6. novembra 1920 v Unionu«. Dom in svet 33.11/12 (1920): 315-316.

Kocijan, Gregor. Slovenska kratka proza: 1919-1929. Ljubljana: Založba ZRC, ZRC SAZU, 2012.

Kos, Matevž. »Šorli, Albreht, Nietzsche«. Jezik in slovstvo 46.7/8 (2000/2001): 325333.

Kos, Matevž. „Vprašanje o Podbevškovem 'pesniškem molku' «. Jezik in slovstvo 54.5 (2009): 3-13.

Kralj, Lado. »'Jaz sem barbar': barbarstvo kot motiv in ideologija v avantgardistični literaturi«. Primerjalna književnost 11.1 (1988): 29-41.

L.[ah], I.[van] in G.[ovekar], F.[ran]. "Slovenska najmlajša». Jutro 23. 9. 1921.

Legiša, Lino. "V ekspresionizem in novi realizem«. Zgodovina slovenskega slovstva VI. Ur. Lino Legiša. Ljubljana: Slovenska matica, 1969.

Lethen, Helmut. Verhaltenslehren der Kälte. Lebensversuche zwischen den Kriegen. Frankfurt am Main: Suhrkamp, 1994.

Marinetti, Filippo Tommaso. "Rapporto sulla vittoria del Futurismo a Trieste«. L'Incendiario, col rapporto sulla vittoria futurista di Trieste. Aldo Palazzeschi. Milano: Edizioni Futuriste di »Poesia«, 1910. 9-22.

Marinetti, Filippo Tommaso. Guerra sola igiene del mondo. Milano: Edizioni Futuriste di »Poesia«, 1915.

Mušič, Marjan. Novomeška pomlad. Maribor: Obzorja, 1974.

Ocvirk, Anton. "Pesništvo (Literarni pregledi)«. Ljubljanski zvon 49.12 (1929): 705 713.

Pahor, Boris. Srečko Kosovel. Pričevalec zaznamovanega stoletja. Ljubljana: Znanstvena založba Filozofske fakultete, 2008.

Petrè, Fran. »Podbevškov problem«. Naša sodobnost 4.7/8 (1956): 674-692.

Pizzi, Katia. »'Qualè triestinità?' Glasovi in odmevi iz italijanskega Trsta«. Primerjalna književnost 28 (2005): 103-114.

Podbevšek, Anton. Moje ekstaze skulptura. Znanstvenokritična izdaja pesniškega opusa. Ur. Marijan Dović. Ljubljana; Novo mesto: Založba ZRC, ZRC SAZU; Založba Goga, 2008.

Poniž, Denis. "Slovenske zgodovinske avantgarde med Podbevškom in Tankom». Filologičeskie zametki. Vyp. 2: mežvuzovskij sbornik naučnyh trudov. Ur. Marija P. Kotjurova. Perm; Ljubljana: Permskij universitet, 2003. 165-180.

Poniž, Denis. "Sedem desetletij Človeka z bombami«. Človek z bombami. Avtor Anton Podbevšek. Novo mesto: Dolenjska založba, 1991. 9-34.

Pranjić, Kristina. "Zenitistični koncept barbarogenija kot kritika zahodnoevropske kulture«. Primerjalna književnost 43.3 (2020): 139-157.

Rehage, Georg Philipp. 'Wo sind Worte für das Erleben'. Die lyrische Darstellung des Ersten Weltkrieges in der französischen und deutschen Avantgarde (G. Apollinaire, J. Cocteau, A. Stramm, W. Klemm). Heidelberg: Universitätsverlag C. Winter, 2003. 
Rehar, Radivoj. „Človek z bombami«. Tabor 9. 6. 1921.

Remec, Alojzij. »Anton Podbevšek: Človek z bombami«. Slovenec 16. 11. 1920.

Stelè, France. "Recitacijski večer Antona Podbevška«. Dom in svet 34.1/3 (1921): 59-61.

Šalamun - Biedrzycka, Katarina. Anton Podbevšek in njegov čas. Maribor: Založba Obzorja, 1972.

Toporišič, Tomaž. "Nevarna razmerja 'mlade slovenske umetnosti' in futurizma». Primerjalna književnost 37.3 (2014): 1-21.

Troha, Vera. "O Kosovelu in italijanskem futurizmu«. Primerjalna književnost 11.2 (1988): 1-14.

Vidmar, Josip. »Urednikov uvodnik«. Kritika 1.4 (1925): 1-3.

Vidmar, Josip. »A. Podbevšek: Človek z bombami«. Kritika 1.4 (1925): 54-58.

Vidmar, Josip. "Slovenska zgodovinska avantgarda 1910-1930«. Sodobnost 33.3 (1985): 302-305.

Vodnik, France. "Anton Podbevšek: Človek z bombami«. Dom in svet 38.4 (1925): 254-255.

Vrečko, Janez. "Labodovci, pilotovci, konstrukterji, konsisti in tankisti«. Slavistična revija 47.1 (1999): 49-67.

Vrečko, Janez. Srečko Kosovel. Ljubljana: Založba ZRC, ZRC SAZU, 2011.

Vrečko, Janez. "Barbarogenij, barbarsko in fašizem». Primerjalna književnost 35.3 (2012): 261-270.

\section{The Slovenian Historical Avant-garde in the Context of the Experience of the First World War, Nationalisms, and Fascism: The Case of Anton Podbevšek}

Keywords: Slovenian literature / historical avant-garde / Podbevšek, Anton / World War I / futurism / nationalism / Italian fascism

Slovenian historical avant-garde (ca. 1915-1927) was formed in the context of the experience of the First World War, the rise of nationalisms, and Italian fascism. The article focuses on Anton Podbevšek, a pioneer of the Slovenian avant-garde and an artist whose literary performances and poems hit the raw nerve of the Slovenian cultural space. Podbevšek introduced himself to his audience with his name and title of his poetry collection: Anton Podbevšek - The Man with the Bombs (Človek z bombami). The title, Podbevšek said, was a reflection of the then war times. The article challenges the assumption that in the early stages of his poetic career, Podbevšek was fascinated by futurism and that, under its influence, he was 'magically 
attracted' to war. It illustrates that rather than futuristic language experiments, the poem cycle "Yellow Letters" (Žolta pisma) recalls the horrors of war and the language of trauma. The analysis shows that the wording and the sensuous-concrete presentation of the experienced ordeals beyond aestheticisation are essential characteristics of Podbevšek's art. Many contemporaries 'intuitively' recognised themselves therein, sympathetically reliving it. However, despite the fascination it aroused, it had to bow to the nationalist and/or militant-inspired 'Future Builders'. The article also addresses the construct of the Balkan 'barbarian genius' and the ambivalent attitude of (especially coastal) Slovenian avant-garde artists towards the Italian futurism due to its ties with irredentism and fascism.

1.01 Izvirni znanstveni članek / Original scientific article UDK 821.163.6.09Podbevšek A.

D0I: https://doi.org/10.3986/pkn.v44.i2.10 